\title{
RIFAMICINA SV EN LA HISTERECTOMIA VAGINAL
}

\author{
Dr. Jaime Díaz Garzón
}

Instructor Asociado del Departamento de Obstetricia y Ginecología. (Facultad de Medicina de la Universidad Nacional).

\section{Dr. Ignacio Delgado Ortiz}

Residente del Departamento de Obstetricia y Ginecología. (Facultad de Medicina de la Universi-

dad Nacional).

Indudablemente el método de elección para corregir el prolapso genital de II o III grado, en pacientes aptas para ello, es la operación de Mayo modificada (1), es decir, la Histerectomía Vaginal con corrección de celes. Sinembargo, es bien sabido que esta intervención tiene como problemas su gran morbilidad infecciosa postquirúrgica $(45.2 \%)$ (2), a pesar de las precauciones pre e intraoperatorias que se tomen (mejorar el estado general, estrogenoterapia en menopáusicas, tratamiento de colpitis, cervicitis, asepsia y antisepsia rigurosas, etc.).

Por lo anterior, y con la intención de disminuir en lo posible la acción de los gérmenes que pudieran por cualquier motivo estar presentes durante el acto quirúrgico, decidimos utilizar un bactericida local. Para tal objeto escogimos la Rifamicina SV antibiótico elaborado a partir del hongo Streptomyces Mediterranis, de intensa acción sobre los gérmenes Gram positivos, inclusive a concentraciones de cinco (5) mcgr. x cc., y también sobre gérmenes Gram Negativos a concentraciones de 50-100 mcgr. x cc. (3). Clínicamente han sido demostrados los buenos resultados de la aplicación local de este antibiótico en casos de sinusitis, úlceras cutáneas, etc. $(4,5,6)$.

El motivo de esta comunicación es dar a conocer nuestros resultados con este procedimiento.

\section{Material y Métodos}

Esta experiencia se llevó a cabo en el Servicio de Ginecología del Instituto Materno Infantil "Concepción ViIlaveces de Acosta", de Bogotá (Colombia ).

De un grupo de 60 mujeres programadas para ser histerectomizadas por vía vaginal, 30 fueron tomadas como control; a las 30 restantes, durante el acto operatorio, se les inyectó por debajo de la mucosa vaginal, alrededor del cuello, el contenido de una ampolla de Rifamicina SV de 250 mg. disuelta en $25 \mathrm{cc}$. de solución salina. Esto de paso, facilitó enormemente la disección y rechazo de la mucosa. La misma solución antibiótica se aplicó, además, en los pedículos y zonas cruentas. Los cirujanos 
no fueron siempre los mismos; actuaron como tales, fuera de los docentes, los médicos adscritos al programa de especialización en el Departamento de Obstetricia y Ginecología.

En el post-operatorio, a todas las pacientes se les dejó sonda vesical a permanencia, se les administraron sulfas con la intención de prevenir la posible infección urinaria. También a todas aquellas enfermas - tanto del grupo control como del grupo en estudio- que hicieron fiebre, se les administraron antibióticos (Penicilina-Streptomicina).

\section{Resultados}

No hubo ninguna defunción en el grupo total de pacientes intervenidas.

En el grupo control, 14 pacientes $(46,6 \%)$, hicieron estado febril postoperatorio, demostrándose en 2 de ellas absceso de la cúpula vaginal. El promedio de hospitalización postoperatoria fue de 7.9 días.

En el grupo de estudio hubo $8 \mathrm{ca}$ sos febriles ( $26.6 \%)$, pero en ninguno se demostró absceso de cúpula, siendo el promedio de hospitalización de 5.2 días.

\section{Comentario}

Por los anteriores resultados podemos deducir que la morbilidad infecciosa se reduce sensiblemente cuando se utiliza la Rifamicina en aplicación local durante la Histerec- tomía Vaginal. Sinembargo, como dichos resultados no son aún completamente satisfactorios, creemos que se deben extremar todas las precauciones, especialmente las relacionadas con la curación de flujos, colpitis, cervicitis, etc.

\section{Resumen y Conclusiones}

A treinta pacientes que fueron sometidas a Histerectomía Vaginal, se les aplicó localmente durante el acto operatorio Rifamicina SV.

Al comparar los resultados con un grupo control numéricamente igual se apreció una disminución de la morbilidad infecciosa post - operatoria.

\section{BIBLIOGRAFIA}

1 MAYO C. H. Uterine prolapse with associated pelvic relaxation. Surg., Gynec. Obstet. 20: 253, 1915.

2 RODRIGUEZ SOTO, ARTURO: “Histerectomía". Rev. Col. de Obs. y Gin., Bogotá, Vol. 12: 295, 1961

3 TIMBUL, M. T., PALLANZA, R., CARNITTI G.: Bacteriological studies of Ryfomycin SV, in vitro. "In Farmaco". Marzo 1961, № 3.

4 LALOUX, E.: Quelques observations sur 18 emploi local de la Rifamicine SV, en dermatologie. Bruxelles Medical, 45e année, No 51, 19 décembre 1965, pp. 1.927.

5 A. BIANCHI MAIOCCHI: Drenaggie: continuo a applicazione locale di Rifamicina SV nell ostiomielite cronica. Ohemoterapia: 7: 344. 349. 1963.

6 MALINES: La Rifamycine dans le trantement local des infections des sinus de la face. "Scalpel" No 4, Février 1967. 